\title{
Altruism, Selfishness and Social Cohesion
}

\author{
Antonio Luigi Paolilli \\ University of Salento, Lecce, Italy. \\ Email: apaolilli@alice.it \\ Received May $1^{\text {st }}, 2011$; revised July $8^{\text {th }}, 2011$; accepted September $6^{\text {th }}, 2011$.
}

\begin{abstract}
Recently has been shown that, given certain conditions, altruism can prevail in a population even without the help of mechanisms as kin selection, reciprocal altruism and group selection. At the light of this hypothesis, it is shown how altruism and cooperative aptitudes can favor the concentration of a population and how an (incomplete) evolution of altruism, caused by group selection, into the Benthamian form, determining the emergence of sentiments and behaviors, such as a sense of justice, as well as envy and gossip, can lead to the formation of a regulated society. From this standpoint, altruism leads to group selection, and not the contrary.
\end{abstract}

Keywords: Altruism, Selfishness, Group Selection, Economic Development

\section{Introduction}

The principal theories adopted to explain the emergence of altruistic behaviors in the human genre are kin selection, reciprocal altruism and group selection. Recently has been shown that, given certain conditions (mainly a rise in marginal outputs due to the increasingly altruistic aptitudes of agents), altruism can prevail in a population even without the help of these mechanisms.

In the light of the latter hypothesis, this work shows that altruism and cooperative attitudes can work in favor of population concentration and therefore, after the emergence of altruism or at least cooperative attitudes, can trigger group selection. The latter, in turn, favors an (incomplete) evolution of altruism into the Benthamian form, bringing out sentiments and behaveiors, such as a sense of justice, as well as envy and gossip, which can lead to the formation of a regulated society.

From this standpoint, altruism leads to group selection, and not the contrary.

The paper is organized as follows.

Section 1 is an overview of the literature about the origin of altruism. Section 2 is devoted to define the reasons at the basis of the concentration of a population. In Section 3 a model describing the concentration process is presented. Section 4 illustrates the nature and the genesis of some internal control mechanisms, already mentioned in Section 2.

\section{The Origin of Altruism: An Overview}

The problem of the origin of altruism has been at the centre of a wide debate.

The principal theories adopted to explain the emergence of altruistic behaviors in the human genre are kin selection, reciprocal altruism and group selection.

The thesis of group selection (Winne-Edwards, 1962) asserts that altruism involves cooperation and the internal cohesion of a group, thus favoring its survival (Sober, 1991). This thesis has been challenged by many evolutionists who think that, as the unit of reproduction in humankind is not the group but the individual, selection might favor those characteristics that maxi-

${ }^{1}$ For the limits of our reasoning in conditions of uncertainty, see (Tversky \& Kahneman, 1974), (Cosmides \& Tooby, 1996), (Gigerenzer \& Hoffrage, 1995). mize individual utility, thus operating against altruism. (Williams, 1966), in particular, argues that even if group selection is theoretically possible, it's role in nature is insignificant. This happens because any level of the biological hierarchy requires a process of natural selection which operates at that level, and this is a very rare event, due to the fact that, in Williams's view, the fundamental unit of selection (the replicator, in Dawkins' terminology, 1976) is the gene. In fact, in this framework even individuals which are sexually reproducing organisms cannot be units of selection because they are not faithfully replicated.

Evolutionary biologists, therefore, have given greater support to the thesis of kin selection (or inclusive fitness theory), which holds that a subject's altruistic behavior is directed mainly toward his relatives. In this framework (Eberhard, 1975) has mathematically shown that also small degrees of consanguinity can constitute the basis for kin selection, and this is true, above all, with low costs for the benefactors.

Another approach is reciprocal altruism, in which selection can favor altruism even if it is directed at individuals with no degree of consanguinity, as long as there is reciprocity. An important condition to permit this outcome, therefore, is that cooperation is based on prize-punishment mechanisms. Important contributions on this point are the Tit-for-Tat strategy (Axelrod \& Hamilton, 1981), the Ultimatum Game, introduced by (Güth et al., 1982) (see also Güth, 1995; Witt \& Yaary, 1992), and the Gift Exchange Game (Fehr, et al., 1993). Altruism, in this context, might be the consequence of a rational choice.

However, in one particular game, the Dictator Game, in which there is a responder who can only accept or refuse the offer made by a proposer, with no consequences for the latter, it has been shown that altruism is not absent (Forsythe et al,1994), and this is in contrast with the concept of altruism as a rational choice, drawing attention instead to genetic factors. Many scholars, however, think that genes do not totally explain reciprocal altruism. (Witt, 1985), in particular, places importance on the capacity to learn, a capacity also referred to by (Lorenz, 1994, 1963), for the animal species in general. (Bergstrom \& Stark, 1993) believe that the behavior of an individual can essentially be determined both by genetic factors and by imitation. According to the concept of "bounded rationality" elaborated by (Simon, 1957, 1983, 1992, 1993), there is a gap between the actual behavior and the predictions of rational actor models. In other words, individuals are not able to maximize their objective function if the costs of information collection and process- 
ing are too great, and they therefore have a tendency to act on advice and to respect norms ${ }^{2}$.

However, it cannot be denied that cultural factors, and more generally cognitive factors, are linked to a genetic substratum. Bowles and (Gintis, 2003), for instance, maintain that culture and genes are strongly linked in the human species. (Gintis, 2000), in particular, asserts that humans show manifestations of strong reciprocity, which is a behavior that probably has a genetic component, because it cannot be justified only by cultural or rational motivations. He has also modeled (Gintis, 2003) Simon's explanation of altruism (Simon, 1990), "showing that altruistic norms can "hitchhike" on the general tendency of internal norms to be personally fitness-enhancing".

About the emergence of the genetic predisposition to altruistic behaviors, Sober (Sober \& Wilson, 1996), and (Frank, 1998, 2006), bringing group selection in again, have noted that, using the Price equation (Price, 1970), strategies that are socially beneficial but that give negative outcomes for the individuals adopting them can survive if groups dissolve and remix often enough and if there is a large covariance between traits in associated partners. This happens because groups with a high proportion of altruists have higher than average fitness and therefore grow faster than other groups, increasing the global frequency of the unselfish gene, even if its frequency falls in every group.

The multiple level of selection, above all, is then the central idea of the new group selection approach ${ }^{2}$, which is based on the cognition that "there is one theory of natural selection operating on a nested hierarchy of units, of which inclusive fitness and game theory are special cases" (Wilson \& Sober, 1994). In this context we also find Bowles and (Choi, 2003) who, using an evolutionary game theory model, assert that altruism can emerge if combined with opposing sentiments (like xenophobia), due to the fact that the most cohesive groups tend to prevail in conflicts.

More recently it has been shown, by means of an evolutionary model (Paolilli, 2009), that cooperative aptitudes may have emerged, at least initially, without the help of other mechanisms, and particularly even if the altruists do not discriminate, during their interactions, between altruists and egoists. In other words, the altruists, more inclined to cooperation, prevail upon the egoists, coexist with them or succumb depending on the value of certain parameters, directly linked to the productivity of the interacttions among the agents, or also depending on the initial size of the two populations, without the intervention of punishment mechanisms.

\section{Altruism and Group Relations}

The Paolilli model (Paolilli, 2009), reflecting a Smithian viewpoint and the $\mathrm{x}$-efficiency theory ${ }^{3}$, is based on the assumption that the more the empathy between agents grows, the more intense and numerous trade relations become, thus increasing the output of the system. Indeed, as the work cited mentions, in the environmental context examined (the savannah of the first hominids), trade must be seen as a sharing of work services for

${ }^{2}$ Field (2001) concludes that modularity cognition and the multiple level of selection hold the key to explaining the prevailing of altruism.

${ }^{3}$ The concept of x-(in)efficiency (Leibenstein, 1966, 1973) has been extended by (Altman, 1996, 2001, 2005, 2006), who has shown that in a market both ethical and non-ethical firms, characterized by different x-efficiency levels, can survive.

${ }^{4}$ Naturally the nodal structure of relations will be efficient as long as it does not reach such a level than it overloads the "nodal" subjects. a common purpose, the outcome of which is enjoyed by each agent according to his own degree of altruism and that of the other person.

The model cited gives an explanation of the origin and prevalence of altruism in a population, but has the drawback of only considering binary economic relations (in pairs). However, as is implicitly recognized by (Paolilli, 2009) (the "model, naturally, does not exclude the operating of other ... mechanisms, such as group selection, kin selection and reciprocal altruism"), this approach can be developed. To do this, we must take two important elements into consideration.

The first element is the possibility that the increase of cooperating individuals, at least up to a certain level and for some activities, generates a more than proportional rise in the outcomes, thus favoring the appearance of teams composed by $n$ individuals, with $n>2$.

The second element is the cost (also in terms of time or energy) of the transactions, which, in addition, becomes very important when there are more than two agents interacting simultaneously, due to the exponential increase in possible links between a growing number of agents. The need to reduce interaction costs could determine two important consequences: 1) the stabilization of relations, thus favoring the reduction of uncertainly see (North 1990) and the specialization of actors, who will act in a stable organization, and 2) the concentration of the population, to make the relations easier. The same individual, however, could act in many relations, in pairs or in teams composed of more than or far more than two people, for different activities, and this situation could favor the appearance of complex groups.

The fact that the population is concentrated in stable groups, which contain teams composed of two individuals for some activities and more than two individuals for others, will lead to the appearance of groups characterized of different degrees of internal cohesion. The degree of cohesion, in fact, will depend (directly) on the average propensity for altruism of the group members, and (inversely) on the relational costs. Moreover, the concentration of population, while favoring relations among the members of the group, discourages those among members of different groups. At this point, if two groups are using the same resources, the most productive one (with lower production costs) will prevail, even without war dynamics, increasing its size and spreading its colonies in the space.

The simplest way to reduce the relational costs is to decrease the number of relations in a team composed of more than two individuals, structuring them in a nodal way ${ }^{4}$.

However, as we have seen (Paolilli, 2009), there is no certainty that in every human group the altruists (or cooperative subjects) prevail completely, since intermediate situations are also possible, with the coexistence of altruists and egoists, or at any rate individuals with different degrees of altruism. If two groups, competing for the same resources and possessing the same technological level, are not composed only of altruists, and if both are also structured with teams characterized by nodal relations, the most efficient of the two will prevail, i.e. the group which, besides an aptitude for altruism, also has mechanisms to control the operation of its members.

From this viewpoint, since altruism favors population concentration, it leads to group selection, and not the contrary, as is usually thought. In fact we can claim that the existence itself of a group always requires, if not actual altruism, at least an aptitude for exchanging or cooperating even if it is only for selfish purposes rather than (or as well as) a predatory attitude. 


\section{Modeling Population Concentration}

A simple formalization will be useful to show how and why a population can assemble in one place.

Let us consider the existence of a single population $p$. Moreover, let us suppose that, if the population is dispersed (due to not being cooperative or only by chance) and without technology, every individual needs an area, which we will call place and which will be the surface unit of the territory (assumed as homogeneous).

If a population $p$ assembles in a point ${ }^{5}$, it will experience two opposing consequences: on the one hand, due to the distance from the places and consequent costs, the net output of the places themselves will diminish, and on the other hand, it will increase due to the synergies deriving from the concentration of population. The influence of these synergies will depend on the average degree of altruism (or cohesion) of the group.

The evolution of a group which has a certain technological level and a certain efficiency of internal economic and social relations, can be shown by the following equation:

$$
\mathrm{dp} / \mathrm{dt}=k p\left(S A^{a}-p\right)
$$

It indicates that the population $p$ varies according to a coefficient $k$, its actual size $p$ and the available resources $S A^{a}-p . A$ is the surface of the (circular, given that we assume the homogeneity of the territory) area, expressed in term of places, exploited by the population assembled at its center. $S A^{a}$ is a function of the Cobb-Douglas type and represents the amount of resources available (whose measure unit is the resources necessary for the survival of an individual). The value of $A$ is elevated to the exponent $\alpha$ (whose value is less than 1), which strictly depends on the technological level and will be assumed as a constant. The fact that $\alpha$ is less than 1 means that, as the exploitation area grows, its net marginal productivity decreases, due to the increase of the distance. In fact the concentration of population determines transport costs, even if only in terms of time.

The synergies are indicated by the coefficient $S$, whose value, larger than 1 ( $S=1$ indicates absence of synergies), is strictly dependent on their efficiency, in turn linked to the possible existence of a nodal organization or of control mechanisms ${ }^{6}$.

A population dispersed on an area $A$, then, will assemble at the center of this area only if $S A^{a}>A$ and it will grow until it will equal $S A^{a}$. Also the exploited area $A$ will increase, if the new places are sufficient to the survival of new individuals. We can calculate the maximum value of $A$, i.e. the exploitable area $\left(A^{*}\right)$, making equal to 1 the first derivative of $\left(S A^{a}\right)$, with respect to $A$ :

$$
\alpha S A^{\alpha-1}=1
$$

Then the exploitable area is:

$$
A^{*}=\alpha S^{\frac{1}{1-\alpha}}
$$

The circular exploitable area, however, is obviously a function of the radium which, therefore, is $r=\sqrt{A^{*} / \pi}$. We can also write it as follows:

\footnotetext{
${ }^{5}$ For the sake of simplicity we assume that the concentration happens at a point, rather than on a surface.

${ }^{6} S$ and $\alpha$ are probably linked by a feedback relation, because it is possible that technological progress makes interpersonal relations more efficient, while it is quite certain that the more intense the latter, the more frequent are the innovations, which while often being the output of individual effort, are also favored by culture, evidently linked to a social context.
}

$$
r=\sqrt{\frac{\alpha S^{\frac{1}{1-\alpha}}}{\pi}}
$$

Note that $r$ is expressed in terms of places, i.e. its unitary value is the length of the side of a square whose surface is a place.

Due to the fact that $A^{*}=p r^{2}$, we can insert 3.4 in 3.1 and then, simplifying, we can write:

$$
\mathrm{dp} / \mathrm{dt}=k p\left[S\left(\alpha S^{\frac{1}{1-\alpha}}\right)^{\alpha}-p\right]
$$

The equilibrium values of 3.5 are:

$$
p=0, \quad p=S\left(\alpha S^{\frac{1}{1-\alpha}}\right)^{\alpha}
$$

The first is a trivial equilibrium point and entails the extinction of the group, the second is stable for positive values of $k$.

Observing 3.5' we can easily see that, when the values of parameters $S$ and $\alpha$ (with $\alpha<1$ ) increase, the (potential) population $p$ grows more and more quickly (the value of $k$, instead, if only positive, is not decisive). It should be noticed that, if $S=$ 1 (for the absence of productive relations or synergies), no concentration of population happens: the non trivial equilibrium value (different from 0 ) of 3.5 , in fact, in this case is equal to $\alpha^{\alpha}$, which is less than 1 for $\alpha<1$. This indicates the (obvious) necessity of interpersonal relations and subsequent synergies for every human (and non human) gathering and, above all, it is true for every technological level.

We must underline, in fact, that 3.1 can describe every phenomenon of concentration, at any level, from microscopic (cellular) to macroscopic (population) scale. When from the concentration of some units derives a growth of disposable resources, due to synergies, if the effect of synergies surpasses the cost of exploitation of the area which they exploit, the concentration happens.

Moreover, in the formula the value of $\mathrm{S}$ depends on interpersonal relations, which are not only of altruistic kind. Even the egoists may wish to concentrate in a place. It is sufficient, in fact, that they are available to trade or to cooperate with the other components of the group rather than to prey them, in order to generate synergies, even if more limited see (Forges Davanzati \& Paolilli, 2004) and (Paolilli, 2009).

In the next section we will show that among humans the relations, and therefore the concentration of the population, are driven by a necessary combination of altruism and selfishness.

If two groups, at the same technological level, are so close to each other to compete on the resources, even a small difference in the degree of internal cohesion (here expressed by $S$ ) is obviously enough to determine a clear prevalence of the most cohesive group, especially if they are numerically comparable. In this regard such a behavior has been recently shown by (Paolilli \& Pollice, 2011), even if the model used in that context is different from that we have here presented (particularly the distance between the two groups, for the sake of simplicity, is not explicitly considered).

\section{Group Selection and Its Influence on the Group}

The appearance of more complex types of interpersonal relations (nodal structure, control mechanisms) will lead to different degrees of efficiency in the groups, which will influence 
their capacity to prevail, even without war dynamics ${ }^{7}$.

For this purpose, control mechanisms have a very important role: so we need to explain their origin. We think that the concentration of a population, and the appearance of complex relations among its members, favors the evolution of altruism into the Benthamian kind. Benthamian altruism is characteristically devoted to the group, including however the agent, who sees himself as an element of the group.

The reason for this evolution is the greater productivity of Benthamian altruism in those activities which require cooperation among many agents for a common purpose (in fact Benthamian altruism favors the unity of intents).

It is possible to weight the importance that egoism and altruism have in a decisional process see (Biavati, et al., 2002), Forges (Davanzati \& Paolilli, 2004), in both cases (altruism towards one person at a time and Benthamian altruism). Say $w$ is self interest and $e$ the altruistic motivation, with $w+e=1$. Assuming $w=1$ in the case where the individual acts solely out of self interest, every empathic interest $(e>0)$ for another agent or for the group will reduce the value of $w$, which will therefore be less than 1 . In the first case (altruism towards another agent) the personal benefit of the agent will have, in his decisional process, a weight equal to $w$. If the altruism of the agent, on the contrary, is devoted to a group (Benthamian altruism), composed of $n$ individuals (included the agent), there will be two cases. If the aim of the agent is only the benefit of the group, his personal benefit (and that of every other member of the group) will have, in his decisional process, a weight equal to $1 / n$. If the agent also acts for his personal benefit, i.e. he sees himself also as an individual, as well as a component of the group, his personal benefit will have a weight equal to $w+e / n$. It is important to note see Forges (Davanzati \& Paolilli, 2004) that, while altruism active in binary relations is maximally productive when it influences the decisional process as much as egoism (and not more), i.e. when $e=w$, Benthamian altruism reaches the greatest efficiency in absence of egoistic motivations $(w=0, e=1)$.

This result can be explained by means of two simple inequality systems. The interaction between two agents, named 1 and 2, who are influenced by the first type of altruism, can be represented by the following inequality system:

$$
\begin{aligned}
& w_{1} v_{1}+e_{12} v_{2}>0 \\
& w_{2} v_{2}+e_{21} v_{1}>0
\end{aligned}
$$

where $w_{1}$ and $w_{2}$ measure the weight of self interest in the decisional process of agents ( 1 and 2), $e_{12}$ and $e_{21}$ measure the weight of altruism in the same process, $v_{1}$ and $v_{2}$ are the variation of the utility deriving from the exchange or cooperation for agent 1 and 2 .

Since we set that self interest is reduced by the altruistic motivation $(w=1-e)$, we can see that, while if the agents are both self-interested $\left(w_{1}=w_{2}=1\right)$ the exchange or cooperation happens only if the $v_{1}$ and $v_{2}$ are both positive (direct reciprocal benefit), this is not a necessary condition when the agents are at least partially altruistic (about the survival of altruistic agents interacting with egoists see Paolilli 2009).

\footnotetext{
${ }^{7}$ Moreover we can suppose that the war, among the possible relations between human groups, is only a process of acceleration of events, and for this reason it leads to rather uncertain results: in fact, at least when the technologies of opposite groups are the same, it is more interested by chaotic type dynamics than a slow process, based on an exploitation of the resources obtained by means of work.

${ }^{8}$ This is the case of interaction between pure altruists, i.e. subjects which, when they interact, aim exclusively at their partner's benefit. ${ }^{9}$ For the sake of simplicity we still consider only two agents.
}

Figure 1 shows the possible area of exchanges or cooperation (grey zone), i.e. the area representing the combinations of $v_{1}$ and $v_{2}$ which determine them, having assigned to $e_{12}$ and $e_{21}$ values between 0 and 1 (in the case shown here we have assumed $e_{12}=e_{21}=0.5$ and, consequently, $w_{1}=w_{2}=0.5$ ).

In the case of absence of altruistic motivations $\left(e_{12}=e_{21}=0\right)$ the same area will be confined only to the North-East panel (however while this result may not involve real altruism, it at least involves an aptitude for cooperation, as we mentioned in Section 2). The angle $\sigma$, which contains the area of the possible exchanges or cooperation, grows when $e_{12}+e_{21}$ grows and reaches the maximum value (180 degrees) when $e_{12}+e_{21}=w_{1}$ $+w_{2}$.

When $e_{12}+e_{21}>w_{1}+w_{2}, \sigma$ decreases, returning within ninety degrees, as for self-interested subjects, when $e_{12}+e_{21}=2^{8}$.

If agents are influenced by Benthamian altruism, the inequality system is ${ }^{9}$

$$
\begin{aligned}
& w_{1} v_{1}+e_{1 V T}\left(v_{1}+v_{2}\right)>0 \\
& w_{2} v_{2}+e_{2 V T}\left(v_{1}+v_{2}\right)>0
\end{aligned}
$$

where $e_{1 V T}$ and $e_{2 V T}$ measure the weight of Benthamian altruism in agents' decision-making process (the utility function, instead of containing the other agent's utility variation, has the sum of the utility variations of all the agents interacting). In this case the growth of the cooperation/exchange area, which depends on the increase in $e_{1 V T}$ and $e_{2 V T}$, though slower than with the first kind of altruism, is always positive, and reaches the maximum value (180 degrees) when both $e_{1 V T}$ and $e_{2 V T}$ are equal to 1 , which we can call a case of pure Benthamian altruism.

Figure 2 shows the possible area of exchange or cooperation (grey zone), assuming $e_{1 V T}=e_{2 V T}=0.5$ and, consequently, $w_{1}=$ $w_{2}=0.5$, as in the example of Figure 1 . As we can see, the grey zone is smaller than in Figure 1.

Now we can examine the dynamics of the two types of altruism in a group. In fact even when humans live in a group, they usually do not reduce their personal benefit to $1 / n$, because, unlike social insects, they can all be vehicles of selection. Individuals, therefore, are organs of a group when they act motivated by Benthamian altruism, while they are vehicles of selection when they act on the motivation of self-interest and/or the first type of altruism. In terms of Wilson's thought, in our vision, too, both groups and individuals are vehicles of selection, the former due to Benthamian altruism, the latter due to selfishness and also "binary altruism".

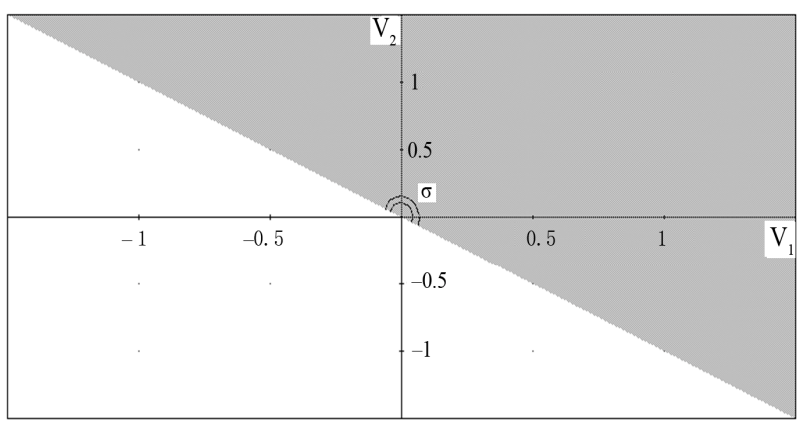

Cinditions: $\mathrm{w}_{1}=\mathrm{w}_{2}=0.5, \mathrm{e}_{12}=\mathrm{e}_{21}=0.5$

Figure 1.

The diagram (in which $v_{1}$ and $v_{2}$ are the "direct" benefit for two partially altruistic actors) shows the possible exchanges (or cooperation) between them. 


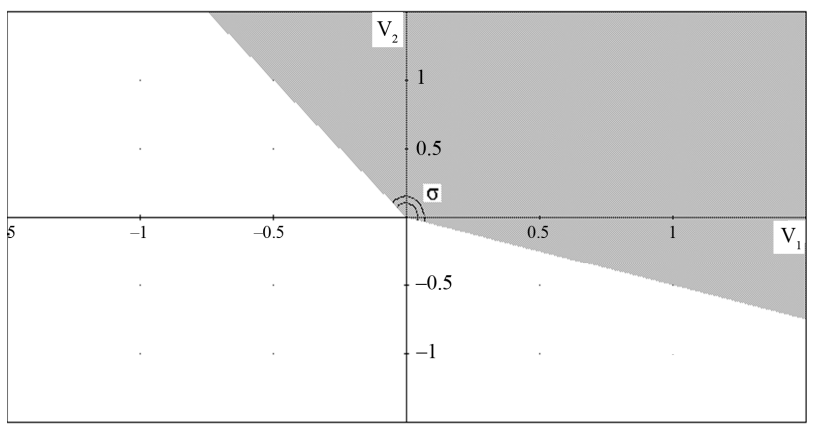

Conditiongs: $\mathrm{w}_{1}=\mathrm{w}_{2}=0.5, \mathrm{e}_{1 \mathrm{VT}}=\mathrm{e}_{2 \mathrm{VT}}=0.5$

Figure 2.

The diagram shows the possible exchanges (or cooperation) between two partially Benthamian altruists.

When a hierarchic organization of interpersonal relations appears, therefore, many binary relations continue to exist. In modern societies, for example, this happens in friendship and in the market; the same teams interact in the market by means of binary relations. In these relations, as we have pointed out, the presence of egoism, beside altruism, increases effort and therefore productivity.

However, if a person who gives to an egoist acts because he is moved by the first type of altruism, this action, if it is perceived as detrimental to the group, will be hampered by the Benthamian altruists. Benthamian altruism can thus be related to the sense of justice see (Khalil, 2003) $)^{10}$.

At the light of these considerations we can also explain the genesis and the role of sentiments and behaviors, such as envy and gossip, seemingly the opposite to altruism, but which have a great effect on human behavior ${ }^{11}$. Envy is a perception that someone else unjustly or without merit obtains resources or status and is essentially an outcome of the interaction between Benthamian altruism and selfishness.

Gossip, on the other hand, is the morbid aspect of the informative activity (but it is precisely its morbidity that makes this activity attractive), in turn a consequence, and necessary for the aims of Benthamian altruism itself. If regarded from this viewpoint, behaviors and sentiments usually detested, but very widespread, such as gossip and envy (the former partially dependent on the latter; another cause of gossip could be admiration and the spirit of emulation, attitudes we can define as adaptive, because they incentive the productivity), are justified by the social control that they permit. They are essentially attitudes which, as long as they do not destroy the cooperative spirit, can be productive for the group, in a context like the human one in which, due to the fact that all individuals are vehicles of selection, selfishness cannot disappear.

\section{Conclusions}

We can conclude that evolution may have favored the emergence in humans of altruistic attitudes for the reasons evidenced

\footnotetext{
${ }^{10}$ Though (Alexander, 1987) does not believe in group selection, he compares human moral systems to the genetic rules of meiosis. As the latter eliminate fitness differences among genes, human moral systems have the same role for the members of a group.

${ }^{11} \mathrm{Envy}$, in particular, and its role, have been studied by several scholars (see, among others, Vignolo, 2005), about the role of envy in coordination).
}

by (Paolilli, 2009), i.e. the existence of growing marginal outputs dependent on the effort of the agents. However, the probable existence, for some activities, of average outputs that grow depending on the increase in cooperative subjects, may have favored the appearance of teams composed of more than two individuals. Moreover, the need to reduce the interaction costs stimulated more stable relations, leading to a concentration of populations in the space. This concentration favored the emergence of group selection. In competition for common resources, the more efficient groups prevailed, and precisely those which had, along with Benthamian altruism (typically devoted to the group), developed a nodal organization in teams composed of more than two individuals and between teams as well. They had also developed more efficient control mechanisms (sense of justice and, in some cases, also envy and gossip). These control mechanisms are a direct consequence of Benthamian altruism and its interaction with selfishness, which maintains its utility at least in binary relations and at any rate cannot disappear from the human genre since all humans are vehicles of reproduction and selection. From this viewpoint, therefore, altruism generates groups (there are no groups without altruism or, at least, cooperative attitudes), and it is only after this that group selection stimulates, rather than the prevalence of altruism within the groups, its evolution into Benthamian altruism and the appearance of control mechanisms.

\section{References}

Alexander, R. D. (1987). The biology of moral systems. New York: Aldine de Gruyter.

Altman, M. (1996). Human agency and material welfare: Revisions in microeconomics and their implications for public policy. Boston, Dordrecht, London: Kluwer Academic Publishers.

Altman, M. (2001). Worker satisfaction and economic performance. Armonk, New York: M. E. Sharpe Publishers.

Altman, M. (2005). Reconciling altruistic, moralistic, and ethical behavior with the rational economic agent and competitive markets. Journal of Economic Psychology, 26, 732-757.

doi:10.1016/j.joep.2005.06.004

Altman, M. (2006). Opening-up the objective function: choice behavior and economic and non-economic variables-core and marginal altruism. Economics Bulletin, 4, 1-11.

Axelrod, R., \& Hamilton, W. D. (1981). The evolution of cooperation. Science, 211, 1390-1396. doi:10.1126/science.7466396

Bergstrom, T. C., \& Stark, O. (1993). How altruism can prevail in an evolutionary environment. The American Economic Review, 83, 149155.

Biavati, M., et al. (2002). Preferenze endogene e dinamiche relazionali: Un modello coevolutivo. In P. L. Saccoand, \& S. Zamagni (Eds.), Complessità relazionale e comportamento economico (pp. 431-485). Bologna: Il Mulino.

Bowles, S., \& Gintis, H. (2003). The origins of human cooperation. In P. Hammerstein (Ed.), Genetic and cultural evolution of cooperation. Cambridgwe, MA: MIT Press, 430-443.

Bowles, S., \& Choi, J.-K. (2003). The co-evolution of love and hate. Quaderni, 401, Università degli Studi di Siena.

Cosmides, L., \& Toby, J. (1996). Are humans good intuitive statisticians after all? Rethinking some conclusions from the literature on judgment under uncertainty. Cognition, 58, 1-73. doi:10.1016/0010-0277(95)00664-8

Dawkins, R. (1976), The selfish gene, Oxford: Oxford University Press.

Eberhard, M. J. W. (1975). The evolution of social behavior by kin selection. The Quarterly Review of Biology, 50, 1-33. doi:10.1086/408298

Fehr, E., Kirchsteiger, \& G., Riedl, A. (1993). Does fairness prevent market clearing? An experimental investigation. The Quarterly Journal of Economics, 108, 437-459. doi: $10.2307 / 2118338$

Field, A. J. (2001). Altruistically inclined: The behavioral sciences, 
evolutionary theory and the origins of reciprocity. Ann Arbor, MI: University of Michigan Press.

Forges Davanzati, G., \& Paolilli, A. L. (2004). Altruismo, scambi e sviluppo economico. In L. Tundo Ferente (Eds.), La responsabilità del pensare (pp. 289-307). Napoli: Liguori Editore.

Forsythe, R., et al. (1994). Fairness in simple bargaining experiments. Games and Economic Behavior, 6, 347-369. doi:10.1006/game.1994.1021

Frank, S.A. (1998). Foundation of social evolution. Princeton: Princeton University Press.

Frank, S.A. (2006). Social selection. In C. W. Fox, \& J. B. Wolf (Eds.), Evolutionary genetics: Concepts and case studies (pp. 350-363). New York: Oxford University Press.

Gigerenzer, G., \& Hoffrage, U. (1995). How to improve Bayesian reasoning without instruction: Frequency format. Psychological Review, 102, 684-704. doi:10.1037/0033-295X.102.4.684

Gintis, H. (2000). Strong reciprocity and human sociality. Journal of Theoretical Biology, 206, 169-179. doi:10.1006/jtbi.2000.2111

Gintis, H. (2003). The Hitchhiker's guide to altruism: Genes, culture, and the internalization of norms. Journal of Theoretical Biology, 220, 407-418. doi:10.1006/jtbi.2003.3104

Güth, W., et al. (1982). An experimental analysis of ultimatum bargaining. Journal of Economic Behavior and Organization, 3, 367388. doi:10.1016/0167-2681(82)90011-7

Güth, W. (1995). On ultimatum bargaining experiments-A personal review. Journal of Economic Behavior and Organization, 27, 329344. doi:10.1016/0167-2681(94)00071-L

Khalil, E. L. (2003). What is altruism? Journal of Economic Psychology, 1, 97-123.

Leibenstein, H. (1966). Allocative efficiency vs. "x-efficiency". American Economic Review, 56, 392-415.

Leibenstein, H. (1973). Notes on x-efficiency and technical change. In E. B. Ayal (Eds.), Micro-aspects of development (pp. 18-38). New York: Praeger.

Lorenz, K. (1994). L'aggressività. Milano: Il Saggiatore. Italian translation of Das sogenannte böse: Zur naturgeschichte der aggression (1963). Wien: Verlag.

North, D. C. (1990). Institutions, institutional change and economic performance. Cambridge: Cambridge University Press.

Paolilli, A. L. (2009). About the "economic" origin of altruism. The Journal of Socio-Economics, 38, 60-71. doi:10.1016/j.socec.2008.08.006
Paolilli, A. L., \& Pollice, F. (2011). Trajectories of State Formation in Eurasia: a Discussion. Historical Social Research, 136, 343-376.

Price, G. R. (1970). Selection and covariance. Nature, 227, 520-521. doi: $10.1038 / 227520 \mathrm{a} 0$

Reilly, W. J. (1929). Methods for the study of retail relationships. University of Texas Bulletin, Monograph 4, n. 2944.

Simon, H. A. (1957). Models of man: Social and rational. New York: Wiley.

Simon, H. A. (1983). Reason in human affairs. Stanford: Stanford University Press.

Simon, H. A. (1990). A mechanism for social selection and successful altruism. Science, 250, 1665-1668. doi:10.1126/science.2270480

Simon, H. A. (1992). Bounded rationality and the cognitive revolution. Elgar: Aldershot.

Simon, H. A. (1993). Altruism and economics. The American Economic Review, 83, 156-161.

Sober, E. (1991). Organisms, individuals, and units of selection. In A. I. Tauber (Eds.), Organism and the origins of self (pp. 275-296). Dordrecht, Netherlands: Kluwer. doi:10.1007/978-94-011-3406-4 13

Sober, E., \& Wilson, D. S. (1998). Unto others: Evolution and psychology of unselfish behavior. Cambridge, MA: Harvard University Press.

Tversky, A., \& Kahnemann, D. (1974). Judgment under uncertainty: heuristics and biases. Science, 185, 1124-1131. doi:10.1126/science.185.4157.1124

Vignolo, T. (2005). When envy helps explain coordination. Economics Bulletin, 3, 1-7.

Williams, G. C. (1966). Adaptation and natural selection: A critique of some current evolutionary thought. Princeton: Princeton University Press.

Wilson, D. S., \& Sober, E. (1994). Reintroducing group selection to the human behavioral sciences. Behavioral and Brain Sciences, 17, 585654. doi:10.1017/S0140525X00036104

Winne-Edwards, V. C. (1962). Animal dispersion in relation to social behaviour. New York: Hafner.

Witt, U. (1985). Imagination and leadership-the neglected dimension of an evolutionary theory of the firm. Journal of Economic Behavior \& Organization, 35, 161-177. doi:10.1016/S0167-2681(98)00058-4

Witt, U., \& Yaary, M. (1992). An evolutionary approach to explain reciprocal behavior in a simple strategic game. In: U. Witt (Eds.), Explaining process and change-Approaches to evolutionary economics (pp. 23-34). Ann Arbor: University of Michigan Press. 